\title{
A statistical analysis of Pc1-2 waves at a near-cusp station in Antarctica
}

\author{
M. Regi $i^{*} \mathbb{D}$, M. Marzocchetti, P. Francia and M. De Lauretis
}

\begin{abstract}
A statistical study of Pc1-2 waves at southern polar latitudes is presented. Ultra-low frequency geomagnetic field measurements collected at the Italian station Mario Zucchelli (Terra Nova Bay, Antarctica, altitude-adjusted corrected geomagnetic latitude $80^{\circ} \mathrm{S}, \mathrm{MLT}=\mathrm{UT}-8$ ) from 2003 to 2010 corresponding with the declining phase of solar cycle 23 and the onset of the solar cycle 24 are used. The long data series allows us to analyze the solar cycle, seasonal and magnetic local time dependence and investigate the possible generation processes related to the solar wind-magnetosphere interaction. We found that during the day, Pc1-2 waves occur around local magnetic noon and midnight. Polarized waves show an almost linear polarization, suggesting a wave propagation along a meridional ionospheric waveguide, from the injection region up to the latitude of Terra Nova Bay. The origin of the waves appears to be due to substorm/stormrelated instabilities and, in the dayside, to solar wind compressions of the magnetopause. Based on these results, we propose a simple model to estimate Pc1-2 power variations depending on geomagnetic activity and solar wind density.
\end{abstract}

\section{Introduction}

ULF waves in the highest frequency band $(0.1-5 \mathrm{~Hz}$, Pc1-2 waves) have been extensively observed in the magnetosphere and on the ground at both low and high latitudes (Bolshakova et al. 1980; Anderson et al. 1992a, b; Menk et al. 1993; Mursula et al. 1994; Dyrud et al. 1997). They are generally believed to be generated by electromagnetic ion cyclotron (EMIC) resonance in the near equatorial magnetospheric regions, for example, in the storm-time ring current (Menk 2011).

The waves propagate toward the ionosphere along geomagnetic field lines as left-handed polarized Alfven waves. In the ionosphere, after a conversion into righthanded polarized isotropic compressional modes, the waves propagate horizontally in the waveguide represented by the ionosphere, becoming linearly polarized far from the injection region; the major axis of the polarization ellipse points along the direction of wave arrival in the waveguide (Tepley and Landshoff 1966; Greifinger and Greifinger 1968; Greifinger 1972a, b; Summers and Fraser 1972; Fujita and Tamao 1988). Because

*Correspondence: mauro.regi@aquila.infn.it Department of Physical and Chemical Sciences, University of L'Aquila, L'Aquila, Italy ionospheric boundaries are not perfect reflectors, the waves are attenuated during propagation, while leakage through the lower boundary allows their observation on the ground (Manchester 1966).

Frequency time representation of Pc1-2 waves on the ground reveals that they can be generally characterized as structured and unstructured waves.

Structured waves, called "pearls", are characterized by periodic variations in amplitude and have been observed primarily at low and middle latitudes; they are commonly interpreted in terms of wave packets bouncing between conjugate points (Jacobs and Watanabe 1964), as waves modulated by long period ULF waves (Rasinkangas and Mursula 1998; Mursula et al. 2001), or due to a ion cyclotron resonator (Guglielmi et al. 2000), but the formation mechanism has not yet been definitely identified (Paulson et al. 2014, 2017).

Unstructured waves, which do not show a clear repetitive structure, are predominant at high latitudes, suggesting that their source is in the outer magnetospheric regions (Menk et al. 1993; Mursula et al. 1994). The occurrence of waves is characterized by a diurnal variation, with a maximum around noon, and shows an inverse relation with the solar cycle, being significantly 
higher during the solar minimum (Menk et al. 1993; Mursula et al. 1994; Kangas et al. 1998).

Ground and satellite observations (Popecki et al. 1993; Anderson et al. 1996) have suggested that ions of the plasma sheet, drifting from the nightside to dayside, can develop a temperature anisotropy capable of generating EMIC waves; therefore, equatorially generated EMIC waves can represent the source of high-latitude waves. Dyrud et al. (1997) examined Pc1-2 waves at cusp $\left(74^{\circ}\right)$ and polar $\left(80^{\circ}\right)$ latitudes; they found that broadband waves dominated at higher latitudes. Their occurrence was confined around local magnetic noon (within $4 \mathrm{~h}$ ), while narrower bandwidth events are predominant at cusp latitudes and are distributed more widely in local time. The authors suggested that the narrowband waves originated in the subsolar and post-noon equatorial region, while the broadband waves originated in the high-latitude plasma mantle and at the poleward edge of the cusp.

In the outer magnetosphere $(L>9)$, Engebretson et al. (2002) found that most of the observed Pc1-2 waves were associated with compressions of the magnetosphere, due to enhanced solar wind (SW) densities. Analyzing spacecraft and ground data, Usanova et al. (2008) observed structured dayside Pc1 waves at $L=5-6.5\left(63^{\circ}-66^{\circ}\right)$ related to SW density enhancements and magnetospheric compressions, which may be an important source for lower latitude EMIC waves close to the plasmapause. Similarly, Clausen et al. (2011) found that EMIC waves at geosynchronous orbit were preferentially generated during intervals of large SW density, and Tetrick et al. (2017) provided statistical evidence for the association of substorm injections and SW compressions with the onset of EMIC waves at the plasmapause. Usanova et al. (2012), analyzing THEMIS data, observed that EMIC waves occurred preferentially in the dayside outer magnetosphere and are strongly controlled by SW pressure; moreover, high EMIC occurrence, preferentially at 12-15 MLT, is also associated with high AE.

Kim et al. (2011) examined Pc1-2 events simultaneously observed along a meridional array in Antarctica $\left(62^{\circ} \mathrm{S}\right.$ to $87^{\circ} \mathrm{S}$ geomagnetic latitude, spanning $\left.2920 \mathrm{~km}\right)$ during 2007; they found that the waves were observed predominantly during the daytime hours, propagated poleward in the ionospheric waveguide, changed to a linear polarization, and had an attenuation factor of $\sim 10 \mathrm{~dB} / 1000 \mathrm{~km}$.

The importance of Pc1-2 waves as responsible for relativistic electron precipitation into the high-latitude ionosphere has been recently shown with increasing observational evidence (Rodger et al. 2008; Clilverd et al. 2010; Blum et al. 2015). Theoretical studies have demonstrated that such waves should be an effective mechanism for loss of $>1 \mathrm{MeV}$ electrons from the radiation belts, through pitch angle scattering by gyro-resonant interaction (Engebretson et al. 2008, and references therein). The electron precipitation could modify, by ionization, the chemistry and electric conductivity of the atmosphere (Mironova et al. 2015), with potential effects on local or even global climate. In this regard, it is worth noting that a significant correlation between Pc1-2 power and atmospheric parameters has been recently observed in statistical analyses at Terra Nova Bay (TNB) (Francia et al. 2015; Regi et al. 2016, 2017).

In the present work, we conducted a statistical study of Pc1-2 waves in the $100-500 \mathrm{mHz}$ frequency range at southern polar latitudes. We used ULF geomagnetic field measurements collected at the Italian station Mario Zucchelli (Terra Nova Bay, Antarctica, TNB, AACGM latitude $80^{\circ} \mathrm{S}, \mathrm{MLT}=\mathrm{UT}-8$ ) from 2003 to 2010 , corresponding to the declining phase of solar cycle 23 and the onset of solar cycle 24. Although TNB is located in the polar cap, its latitude is such that at magnetic local noon the field line approaches the cusp and closed field lines. The availability of a long time series data allowed us to analyze the solar cycle and seasonal and local time dependence of the observed Pc1-2 waves and investigate their relationship with geomagnetic conditions and SW density.

\section{Data and methods}

We used geomagnetic field fluctuation measurements collected from a search coil magnetometer installed at TNB from 2003 to 2010, with a large data gap during 2005. The instrument provides northward $H$, eastward $D$, and vertically downward $Z$ components of geomagnetic field variations at a 1-s sampling rate. To reduce aliasing, a low-pass filter was applied so that the response at frequencies $>450 \mathrm{mHz}$ was strongly dampened.

We computed, over 30-min intervals, the power spectral density (PSD) and cross-power spectral density (CPSD), using the Hamming window and averaging 200-s subintervals with no overlap, corresponding to a frequency resolution of $5 \mathrm{mHz}$ and 18 degrees of freedom. The spectra were then converted using an instrument transfer function from $\mathrm{mV}^{2} / \mathrm{Hz}$ to $\mathrm{nT}^{2} / \mathrm{Hz}$.

We estimated the polarization parameters applying the technique for partially polarized waves as proposed by Fowler et al. (1967). In particular, the polarization ratio $R$, the ratio between the polarized and total intensities of the horizontal signal, ellipticity $\varepsilon$, the ratio between the minor and major axes of the polarization ellipse in the horizontal plane, and azimuth $\theta$, the clockwise measured angle between the major axis of the polarization ellipse and the $H$ direction, were evaluated over each interval. Looking downward in the southern hemisphere, 
a positive (negative) value of ellipticity indicates lefthanded (right-handed) polarized waves; if the ellipticity is close to zero, generally $|\varepsilon|<0.2$, the waves are linearly polarized.

To characterize the interplanetary and magnetospheric conditions, we used the 1-min SW and interplanetary magnetic field (IMF) data and 1-min geomagnetic activity index $\mathrm{AE}$, respectively, from the OMNI database (http://cdaweb.gsfc.nasa.gov/cdaweb/istppublic/).

\section{Experimental results}

\section{The statistical analysis}

For each 30-min interval, we computed the power on the horizontal $H$ and $D$ components, $P_{H}$ and $P_{D}$, integrated in the Pc1-2 (100-450 mHz) frequency range. Because the power and $\mathrm{AE}$ index typically show variations in several orders of magnitude, when computing time averages, we used $\log (P)$ (Francia et al. 2015; Regi et al. 2015, 2016) and $\log (\mathrm{AE})$ (Anqin et al. 2008; Schmitter 2010) that follow a quasi-normal distribution. The power was then obtained reconverting the results using the exponential function.

Figure 1 shows the sunspot number, 30 -min averages of the SW density and speed, and 30-min averages of the $\mathrm{AE}$ index and total power $P$ (i.e., $P_{H}+P_{D}$ ) through from 2003 to 2010. A large data gap in the ULF power $P$ can be seen during local equinoxes and winter in 2005. The sunspot number clearly shows the long descending phase of solar cycle 23 (2003-2009) and onset of the new activity cycle at the beginning of 2010 . The SW was characterized by recurrent fast speed streams and associated high densities, especially for 2006-2008, while the average speed reached the lowest values in 2009 . The AE index values show a general decrease through the years and exhibit strong variations that closely corresponding to the SW streams. Both the general decrease with the solar cycle and correspondence with the SW stream structure can be observed in the Pc1-2 power, clearly evidenced by the daily averages shown as a red line. In addition, the power is characterized by an annual modulation, with a maximum during the local summer. Figure 2 shows in detail the period from August 15, 2007-January 1, 2008, when recurring SW fast streams are clearly identified, each stream being preceded by enhanced density, which causes the compression of the dayside magnetopause. As shown, the stream structure is well reflected in both the $\mathrm{AE}$ index and daily averages of the Pc power.

From Fig. 2, it is clear that the Pc1-2 power undergoes a diurnal variation. The analysis of this variation is presented in Fig. 3, where we plot the average value of $P$ for each 30-min interval for 2003-2010, separately for summer, winter, and equinoctial months. There is a clear power maximum just after the magnetic local noon (20 UT), when TNB was near the polar cusp and closed field lines. The maximum is less pronounced and slightly shifted during equinoxes, and becomes an order of magnitude lower during winter. We evaluated if such a power maximum reflects a general broadband increase in power or indicates a specific Pc1-2 activity. In Fig. 4, we compare the average of all power spectra around magnetic noon (20 UT, red line) and midnight (08 UT, blue line), separately during summer, equinoctial, and winter months. In addition to a general increase in power at noon with respect to midnight, a clear power enhancement between 100 and $300 \mathrm{mHz}$ characterizes the noon spectra; in particular, this occurs during summer and equinoxes, indicating a specific intensification of Pc1-2 activity.

To clarify if the noon intensification of Pc1-2 power corresponds to a higher occurrence rate of events, we performed an additional analysis, identifying the Pc1-2 events on the basis of the technique developed by De Lauretis et al. (2010) and Ponomarenko et al. (2002). If, for a given time interval, $S_{T}(f)$ is the experimental total (signal + noise) power spectrum, $S(f)$ is the power spectrum of the unknown signal, and $N(f)$ is the background noise, we evaluate the signal-to-noise ratio $\operatorname{SNR}(f)$ as follows:

$$
\mathrm{SNR}=\frac{S}{N}=\frac{S_{T}-N}{N}=\frac{S_{T}}{N}-1
$$

where the noise $N(f)$ was estimated by fitting a linear function to the $\log \left(S_{T}\right)-\log (f)$ dependence at the extremes of the $100-450 \mathrm{mHz}$ frequency range:

$$
\log N=\alpha \log (f)+\beta
$$

For each 30-min interval, if the main SNR peak was higher than a given threshold, we assumed that an event occurred at the corresponding frequency; we considered a threshold of six, which corresponds to a noise less than $15 \%$ of the experimental signal. Impulsive, broadband signals are not selected by our method because their power spectrum does not emerge significantly from the corresponding noise spectrum. For each event, we also conducted a polarization analysis to estimate the polarization ratio, ellipticity, and azimuthal angle. The total number of selected events was 5119; the number of events per day (we applied a smoothing over 31 days) is plotted in Fig. 5 for different years. The most evident feature is the seasonal variation, which is characterized by a clear winter minimum and a maximum extending during summer/equinoxes months. In addition, focusing on the occurrence summer maxima, we note an increase in events from 2005 to 2010, indicating a negative correlation with the solar activity cycle, while the winter minima do not show such a variation. 
The diurnal distribution of the events, normalized to the available data for each 30 -min time interval, is presented in Fig. 6 (black line) for the entire time interval from 2003 to 2010 and separately for summer, equinoctial, and winter months; the error bars in the figure represent the 95\% confidence intervals estimated using the Clopper-Pearson method (Clopper and Pearson 1934; Regi et al. 2014). As shown, the overall events show a predominant occurrence maximum around local magnetic noon and a secondary one, less evident, around midnight. If we restrict the analysis to polarized events, in particular with $R>0.85$ (red line), the occurrence rate is characterized by a very strong attenuation of the noon maximum with respect to the midnight one. This result is generally independent of the choice of the $R$ value above 0.8 ; the choice of $R=0.85$ reduces by no more than $60 \%$ the number of events, still allowing good statistical reliability. The same diurnal distribution is observed for summer and equinoctial events, while winter events are very few and do not clearly show the midnight occurrence maximum.

We investigated the frequency distribution of events detected, respectively, around midnight (Fig. 7, left panel, black line) and noon (Fig. 7, right panel, black line). While the midnight events predominantly occur at frequencies between 200 and $375 \mathrm{mHz}$, for the noon events, the distribution is clearly shifted toward lower frequencies, mostly in the $175-275 \mathrm{mHz}$ range. This result suggests that the Pc1-2 power maximum observed around noon is related to the predominantly lower frequency events occurring in the same time interval; this feature is due to the rapid increase in the power spectrum, with decreasing frequency in the $200-400 \mathrm{mHz}$ range (Fig. 4). In contrast, polarized events are almost uniformly distributed between 200 and $375 \mathrm{mHz}$, both at midnight and noon (Fig. 7, red lines). They are characterized by ellipticity values symmetrically distributed around zero, with $\varepsilon=0.04$ as the median value, indicating an almost linear polarization (Fig. 8, left panel), and by azimuthal angles peaked between $40^{\circ}$ and $70^{\circ}$, with the median value $\sim 49^{\circ}$ (Fig. 8 , right panel), suggesting that the signal power tends to be higher along the east-west component. Similar values of the $\theta$ angle were found at TNB in a different frequency range $(22-100 \mathrm{mHz})$ by De Lauretis et al. (2005); they suggested that the polarization characteristics may be affected by ground conductivity anomalies due to the proximity of TNB to the coastline.

We also investigated the dependence of events on geomagnetic activity and SW conditions. In particular, we considered the $\mathrm{AE}$ index in characterizing the high-latitude geomagnetic activity and SW density $n_{\mathrm{SW}}$, related to magnetospheric compressions, as a SW parameter.

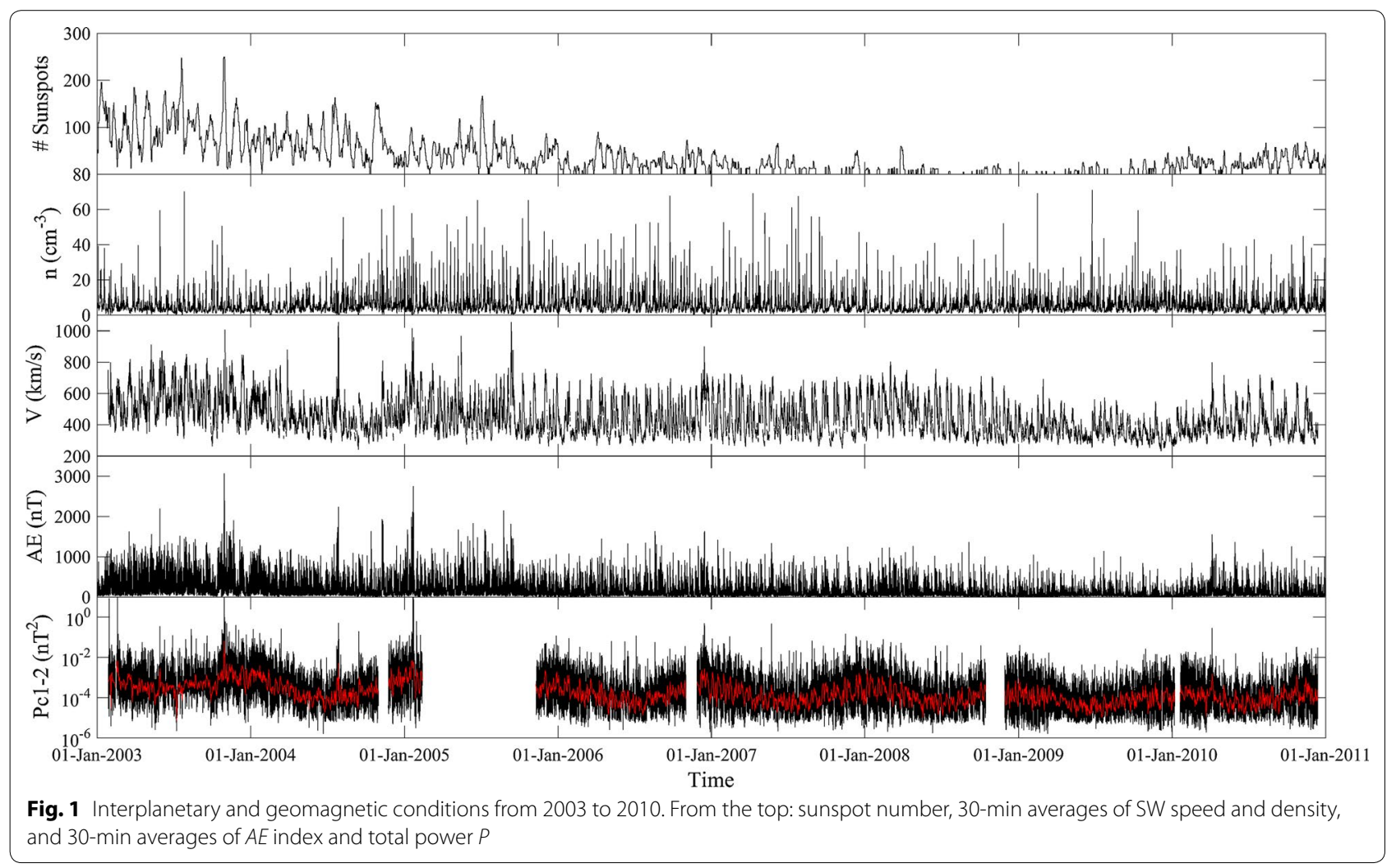




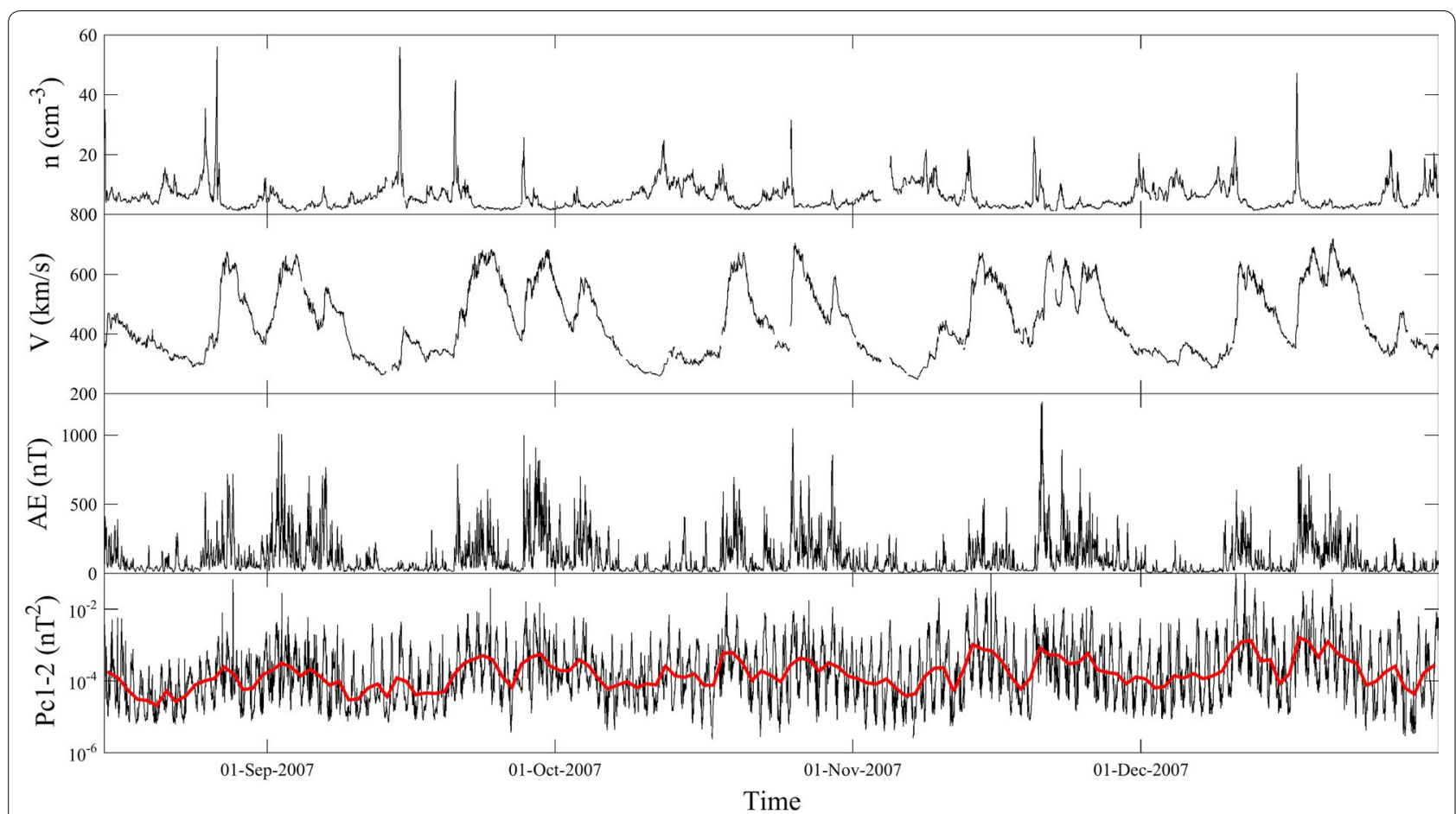

Fig. 2 Interplanetary and geomagnetic conditions in the time interval August 15, 2007-January 1, 2008. 30-min averages of SW density and speed and 30-min averages of AE index and total power

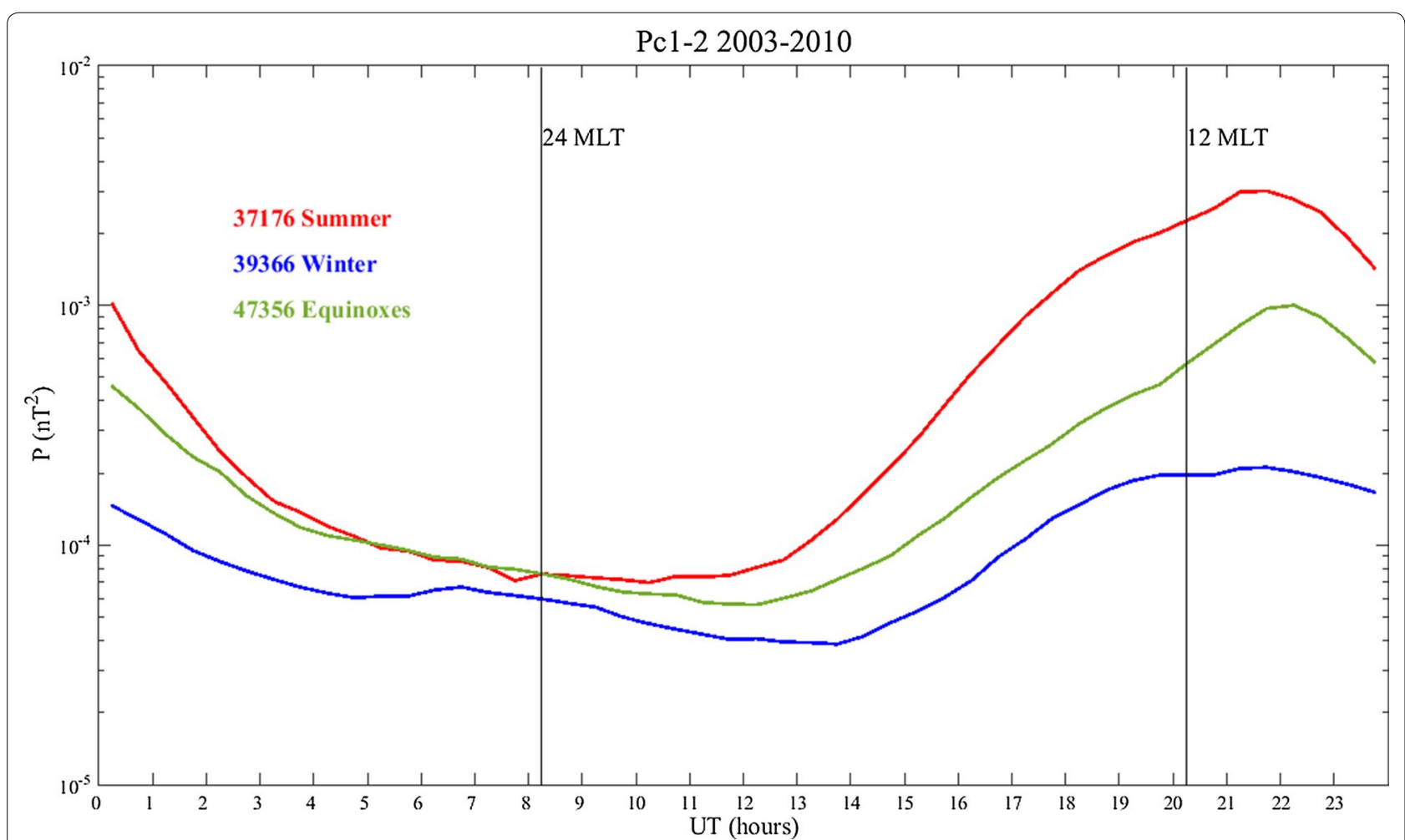

Fig. 3 Daily variations in power. The UT dependence on the average $P$ value from 2003 to 2010, separately for local summer (red line), winter (blue line), and equinoctial (green line) months. The number of spectra in each average is indicated 

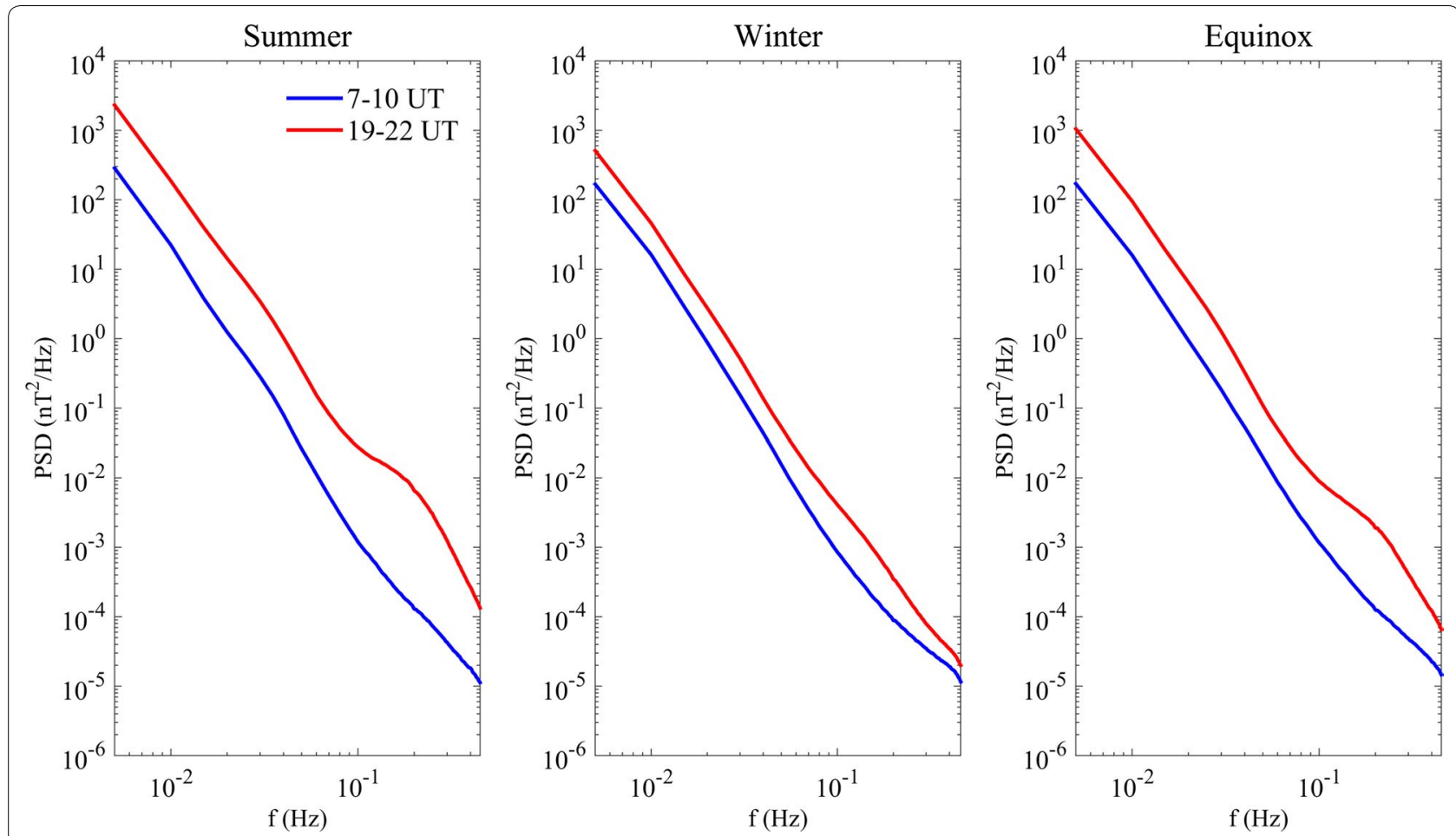

Fig. 4 Average power spectra. The average power spectra around noon (red line) and midnight (blue line), separately for summer (left panel), winter (middle panel), and equinoctial (right panel) months

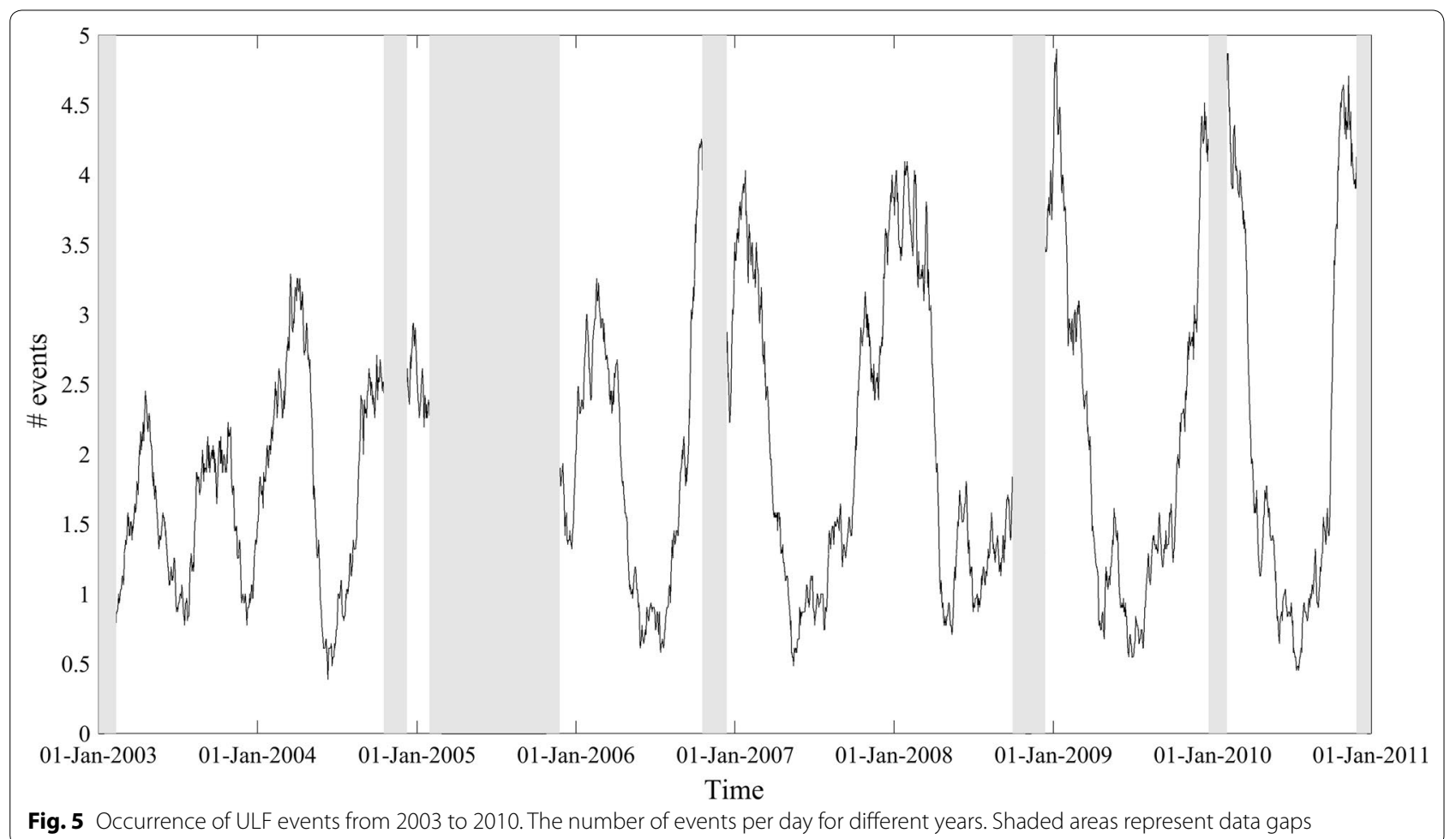



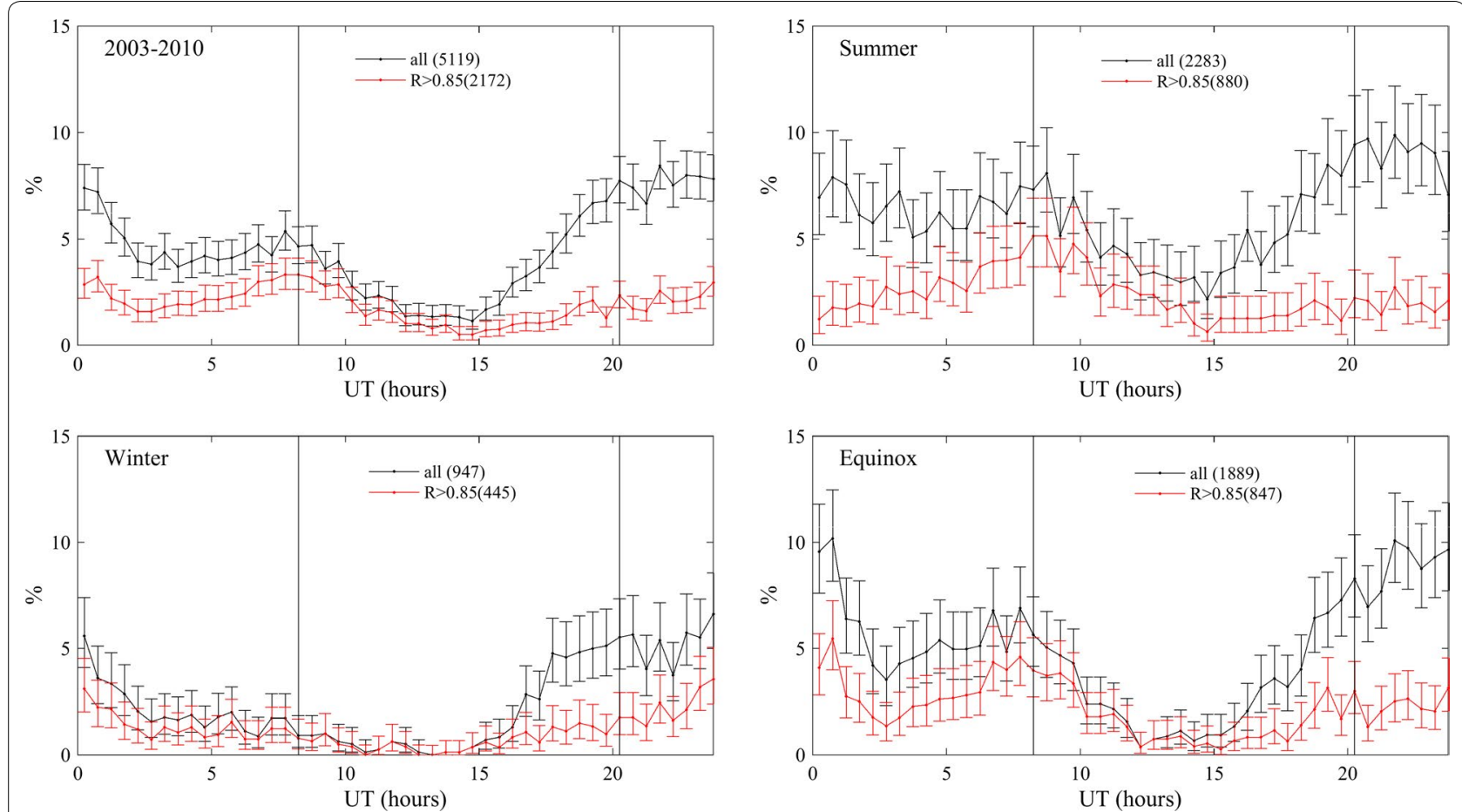

Fig. 6 Daily variation in ULF events. The UT distribution of events, normalized to the available data for each time interval, for the entire time interval, 2003-2010, and separately for summer, equinoctial, and winter months. For each time interval, the number of total events is indicated in parentheses. The vertical lines at approximately 08 UT and 20 UT indicate the magnetic midnight and noon, respectively

Figure 9 shows the distribution of events for disturbed geomagnetic conditions (AE > $300 \mathrm{nT}$, black line) and high SW densities $\left(n_{\mathrm{SW}}>10 \mathrm{~cm}^{-3}\right.$, red line). The midnight maximum of occurrence clearly becomes prevalent with respect to the noon maximum for high $\mathrm{AE}$ values, while it almost disappears for high SW densities. This result indicates that the generation mechanism for Pc1-2 waves observed around midnight is mainly associated with substorm/storm development, while magnetopause compressions cause events almost entirely around noon.

To clarify the relationship between Pc1-2 waves, geomagnetic activity, and SW density, we computed the correlation coefficient between $\ln (P)$ and $\ln (\mathrm{AE})$ and between $\ln (P)$ and $\ln \left(n_{\mathrm{SW}}\right)$ as a function of UT. In this analysis, the total power was integrated in the frequency band where most events were detected, i.e., between 175 and $350 \mathrm{mHz}$. In Fig. 10, we show the results of the correlation analysis, where the $95 \%$ confidence interval is estimated using the null hypothesis. As lustrated, the correlation with the $\mathrm{AE}$ index is significant throughout the entire day, with a maximum at magnetic midnight. The correlation with SW density is not significant, except around magnetic noon, when it does not exceed a value of $\sim 0.2$; we interpret such result as a sporadic correlation, corresponding with high SW density values, which could drive Pc1-2 waves.
Based on the observed results, we developed a simple model that describes $\ln (P)$ as a linear function of $\ln (\mathrm{AE})$ and $\ln \left(n_{\mathrm{SW}}\right)$ :

$$
\ln (P)=a_{0}+a_{1} \ln (\mathrm{AE})+a_{2} \ln \left(n_{\mathrm{SW}}\right)
$$

To estimate $a_{0}, a_{1}$, and $a_{2}$, we first evaluated the hourly values of the intercept and slope obtained from the linear regression analysis; then, the time series of each parameter $a_{i}(i=0,1,2)$ was fitted using four sinusoidal functions as follows

$$
a_{i}=C+\sum_{k=1}^{4} A_{k} \sin \left(\omega_{k} t+\varphi_{k}\right)
$$

where time $t$ represents the hour in UT.

To account for seasonal effects, we performed the analysis separately for summer, winter, and equinoctial months from 2003 to 2010 . The coefficients of the model are presented in Table 1.

As an example, in Fig. 11 we present the UT dependence of the $a_{0}, a_{1}$, and $a_{2}$ coefficients and comparison between the experimental and computed $P$ for March 2008 and January 2016. The comparison is particularly significant for the latter interval, which was not used in computing the model coefficients. We note that $a_{0}$, the basis of the daily variation, is characterized by a 

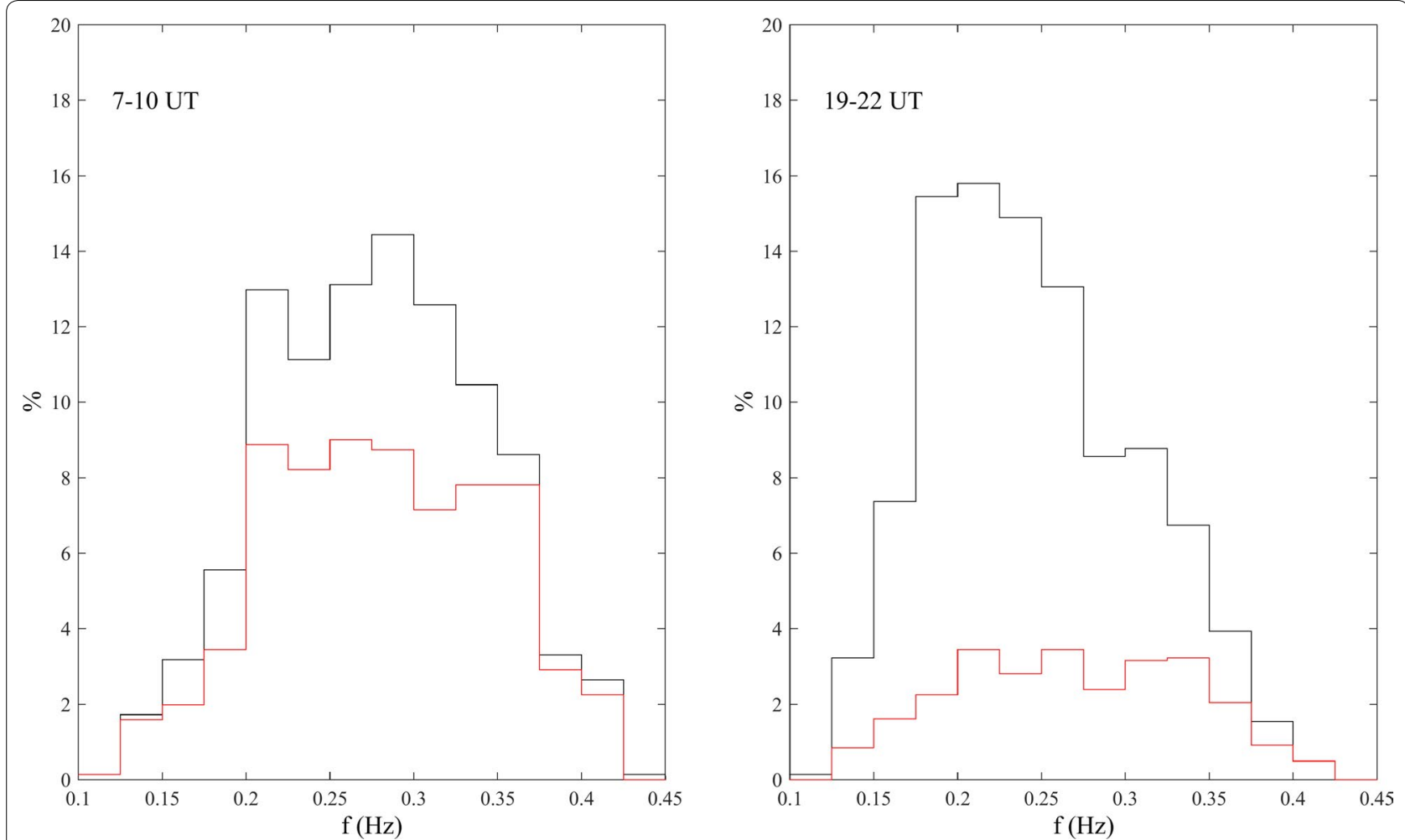

Fig. 7 Frequencies of selected events. The frequency distribution for events around magnetic local midnight (left panel) and magnetic local noon (right panel). The percentages are computed with respect to the number of events for each time interval. Red lines refer to polarized events

maximum just after magnetic local noon during summers and equinoxes, while it is almost constant during winter, as expected in the absence of solar radiation. The $a_{1}$ coefficient shows an additional maximum at midnight, associated with substorm processes, while the $a_{2}$ coefficient only shows a non-negligible contribution around noon; these features are consistent with the observed event distribution during conditions with high $\mathrm{AE}$ and $n_{\mathrm{SW}}$ (Fig. 9). The time series shows a general correspondence for both the selected months, with a correlation coefficient of $\sim 0.8$, and for short-term variations. We also computed the correlation coefficients in different time windows, and, as shown in Fig. 12, we found that the correlation is significant, at a confidence level of $95 \%$, for time scales longer than $6-7 \mathrm{~h}$.

\section{The events}

Here, we show two examples of Pc1-2 events, observed in the noon (Fig. 13) and midnight (Fig. 14) sectors. During the event around local magnetic noon $(20 \mathrm{UT}=12$ MLT) on October 14, 2010, between 17 and 22 UT, the dynamical Fourier spectrum shows a power enhancement at frequencies of $\sim 320-370 \mathrm{mHz}$, lasting several hours and characterized by a signal-to-noise ratio SNR greater than 10. Between 19:30 and 21:10 UT, the polarization ratio $R$ is very high, reaching $\sim 0.90$, the ellipticity value is $\sim 0$, indicating linearly polarized waves, while the azimuthal angle $\theta$ decreases from $\sim 70^{\circ}$ to $\sim 45^{\circ}$. The IMF is directed northward and the geomagnetic index $\mathrm{AE}$ indicates quiet magnetospheric conditions; the SW density is high $\left(>10 \mathrm{~cm}^{-3}\right)$ during the entire time interval. This is an example of Pc1-2 waves associated with magnetospheric compression, which persists for several hours. The compression increases ion anisotropy in the layers just inside the magnetopause, more efficiently in the subsolar region, which stimulates EMIC waves (Usanova et al. 2008, 2012 and references therein); the excited waves propagate along the outermost closed field lines toward the high-latitude ionosphere. They are clearly observed at TNB, where they show a linear polarization together with a decrease in the azimuthal component signal, indicating a transmission along the ionospheric waveguide to a large distance from the injection region (Fujita and Tamao 1988).

Figure 14 shows the event observed on August 27, 2003, just after local magnetic midnight (08 UT $=00 \mathrm{MLT})$. Corresponding to the broadband power enhancements observed in the time interval 09:00-10:00 UT, polarized, short-lived waves in the $300-400 \mathrm{mHz}$ frequency band are observable. They are characterized by an ellipticity 

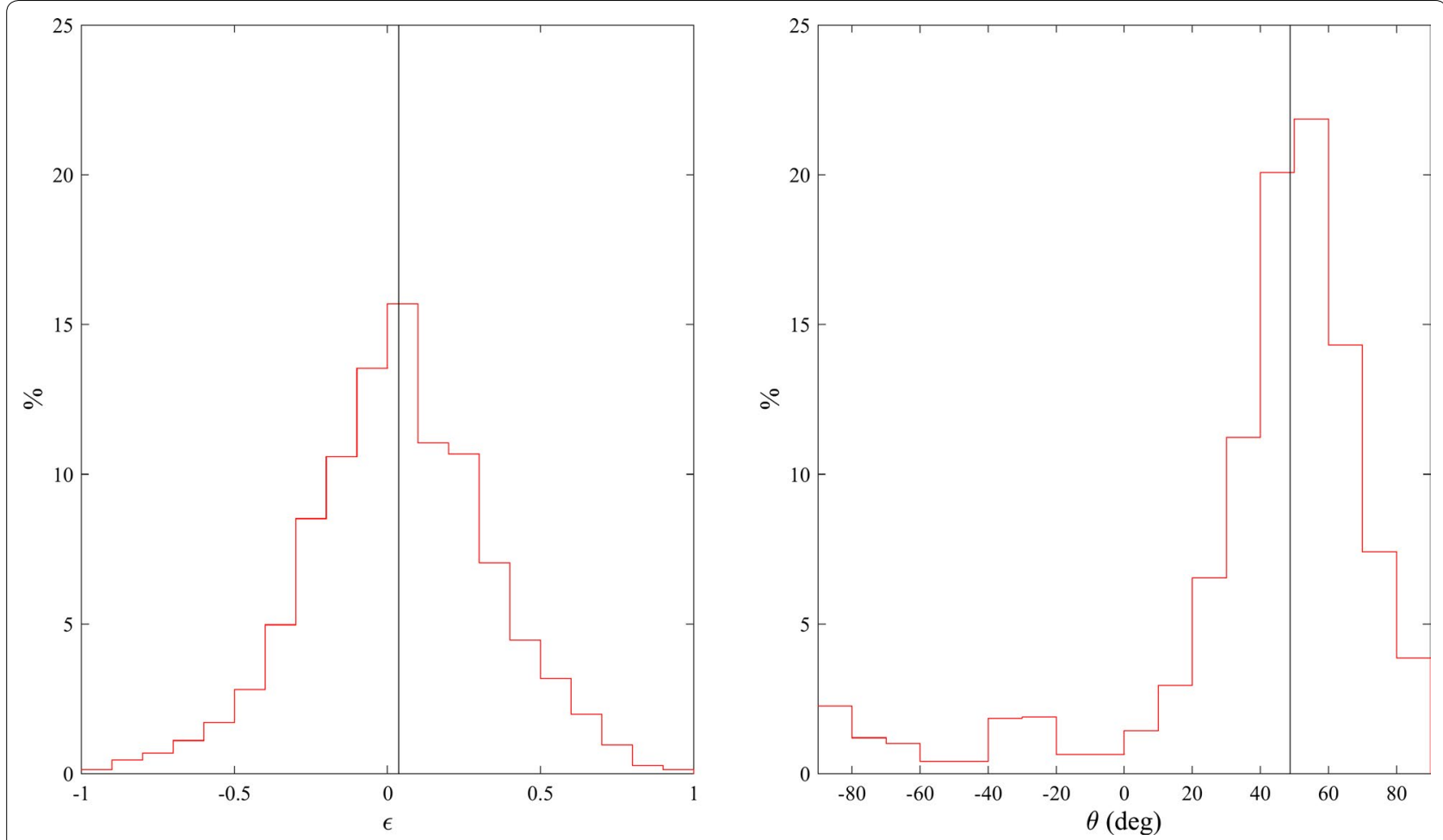

Fig. 8 Polarization parameters. The distribution of ellipticity (left panel) and azimuthal angle (right panel) for polarized events. The vertical black lines mark the median values

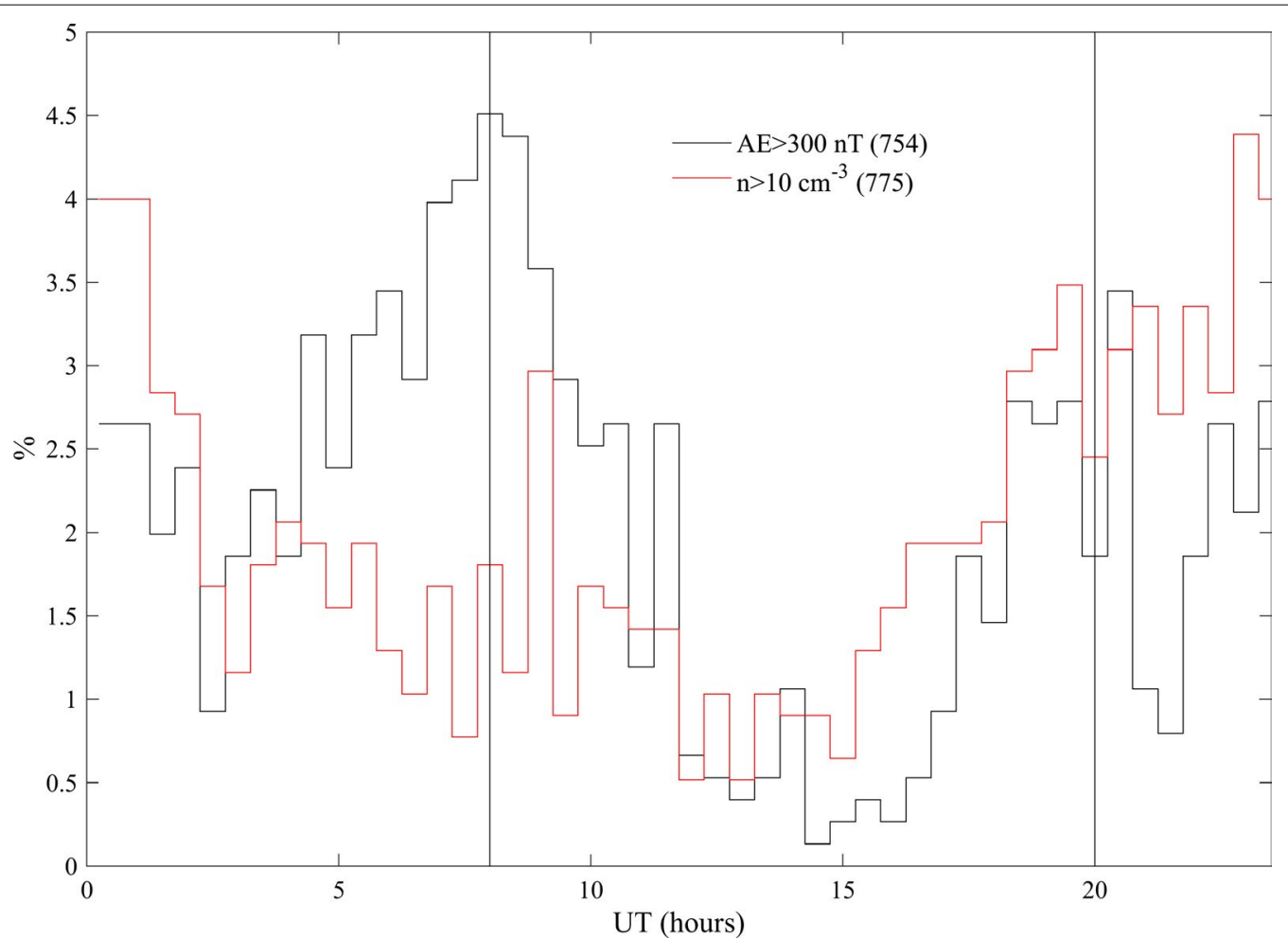

Fig. 9 ULF dependence on AE and solar wind density. The UT distribution of the events for disturbed geomagnetic conditions (black line) and high SW densities (red line). The vertical lines at approximately 08 UT and 20 UT indicate the magnetic midnight and noon, respectively 

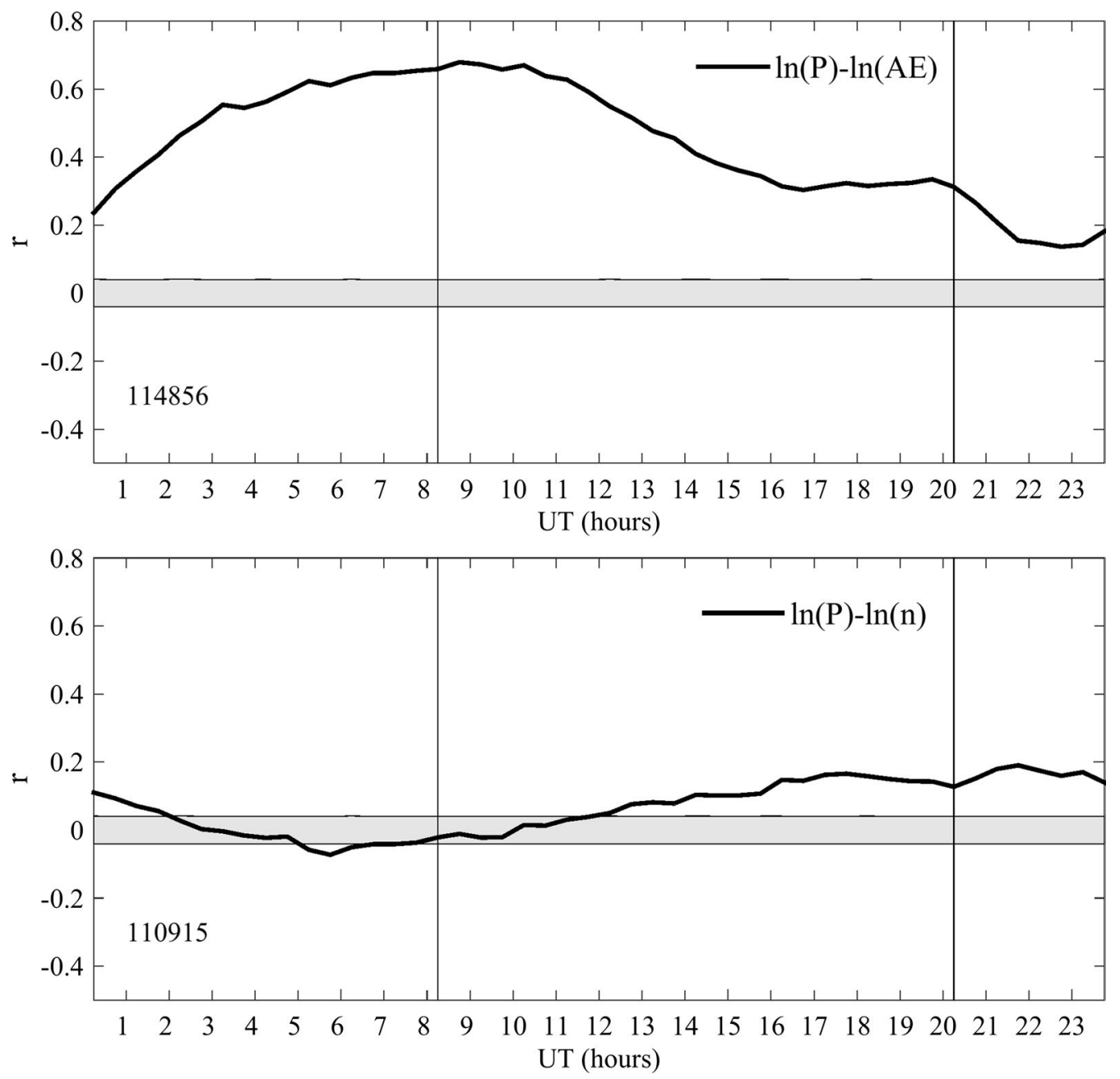

Fig. 10 Correlation analysis. The diurnal variation in correlation between $\ln (P)$ and $\ln (A E)$ (upper panel) and between $\ln (P)$ and $\ln \left(n_{\mathrm{SW}}\right)(\mathrm{bottom}$ panel). The shaded areas indicate the $95 \%$ confidence intervals. In each panel the number of selected time intervals is shown, and the vertical lines at approximately 08 UT and 20 UT indicate the magnetic midnight and noon, respectively

of $\sim 0^{\circ}$ (linear polarization) and a $\theta$ value of $\sim 40^{\circ}-50^{\circ}$. These waves are associated with moderate geomagnetic activity, evidenced by IMF southward fluctuations and an AE index higher than $300 \mathrm{nT}$.

\section{Summary and discussion}

We conducted a statistical study of the Pc1-2 waves at $\mathrm{TNB}$, a southern polar cap station. The geomagnetic latitude $\left(\sim 80^{\circ} \mathrm{S}\right)$ is such that, during the day, the local open field lines approach the magnetopause and closed field lines around noon; it is very close to the latitude of the poleward cusp boundary, particularly during summer and equinoctial months and for northward IMF conditions, i.e., for a quiet magnetosphere (Zhou et al. 1999, 2000).
The long data series, almost continuous in the time interval 2003-2010, allowed us to the study solar cycle and seasonal and daily variations in Pc1-2 power.

We found that the Pc1-2 power seems to follow the solar activity variation, slightly decreasing through the descending phase of the solar cycle (2004-2008) to the solar minimum in 2009. In addition to this weak variation, the Pc1-2 power shows a seasonal modulation, characterized by higher values during the local summer, and a MLT dependence, characterized by a maximum around noon. Both features can be explained, considering that the TNB field lines are at the shortest distances from the outermost closed field lines during summer and around magnetic local noon. Indeed, the latitudinal position of the cusp footprint depends on the dipole tilt 
angle, which exhibits both an annual variation and daily variation. When the geomagnetic dipole axis tilts more toward the Sun, the cusp moves more poleward; Zhou et al. (1999) examined polar cusp crossings at high altitude, obtained from polar satellite data, and showed that the magnetic latitude of the center cusp moves from $\sim 77^{\circ}$ to $\sim 81^{\circ}$, when the tilt angle changes from $-30^{\circ}$ to $30^{\circ}$.

An analysis of Pc1-2 events indicates a seasonal variation, consistent with a similar variation in power. In

Table 1 Model coefficients

\begin{tabular}{|c|c|c|c|c|c|c|c|c|c|c|c|c|c|}
\hline & $C$ & $A_{1}$ & $\omega_{1}$ & $\varphi_{1}$ & $A_{2}$ & $\omega_{2}$ & $\varphi_{2}$ & $A_{3}$ & $\omega_{3}$ & $\varphi_{3}$ & $A_{4}$ & $\omega_{4}$ & $\varphi_{4}$ \\
\hline \multicolumn{14}{|c|}{ Summer } \\
\hline$a_{0}$ & -12.21 & 3.15 & 0.26 & 2.33 & 0.32 & 0.49 & 3.35 & 22.16 & 0.93 & 1.07 & 22.10 & 0.93 & 4.18 \\
\hline$a_{1}$ & 0.55 & 0.32 & 0.25 & -0.63 & 10.34 & 0.94 & -2.60 & 0.06 & 0.57 & -2.58 & 10.33 & 0.94 & 0.53 \\
\hline$a_{2}$ & 0.18 & 0.22 & 0.27 & -2.76 & 0.05 & 0.51 & -2.40 & 0.04 & 3.38 & -1.31 & 0.03 & 1.24 & -1.35 \\
\hline \multicolumn{14}{|c|}{ Equinox } \\
\hline$a_{0}$ & -13.17 & 1.59 & 0.24 & 2.46 & 0.54 & 0.60 & 0.16 & 2.52 & 0.96 & 0.13 & 2.48 & 0.99 & 2.93 \\
\hline$a_{1}$ & 0.59 & 0.17 & 0.24 & -0.19 & 0.16 & 0.54 & -2.64 & 2.98 & 0.99 & -3.51 & 2.99 & 0.99 & -0.41 \\
\hline$a_{2}$ & 0.26 & 0.26 & 0.26 & 2.86 & 0.09 & 0.53 & 2.86 & 5.20 & 1.19 & -4.15 & 5.20 & 1.19 & -1.02 \\
\hline \multicolumn{14}{|c|}{ Winter } \\
\hline$a_{0}$ & -14.91 & 0.54 & 0.26 & 2.58 & 0.43 & 0.59 & -0.34 & 5.21 & 0.97 & -5.77 & 5.18 & 0.98 & 3.58 \\
\hline$a_{1}$ & 0.80 & 0.14 & 0.56 & -3.13 & 0.08 & 0.27 & 0.03 & 0.52 & 0.92 & 0.46 & 0.51 & 0.91 & -2.50 \\
\hline$a_{2}$ & 0.18 & 0.23 & 0.26 & 2.35 & 0.03 & 0.81 & 0.69 & 0.03 & 1.90 & 0.95 & 0.02 & 0.45 & 2.36 \\
\hline
\end{tabular}

The angular frequency is given in $\mathrm{rad} / \mathrm{hour}$
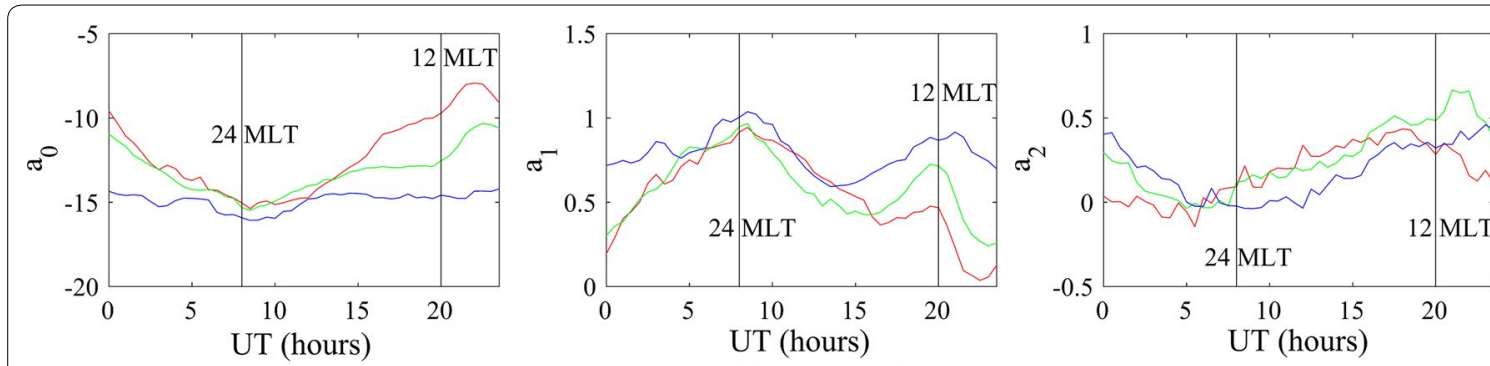

March 2008
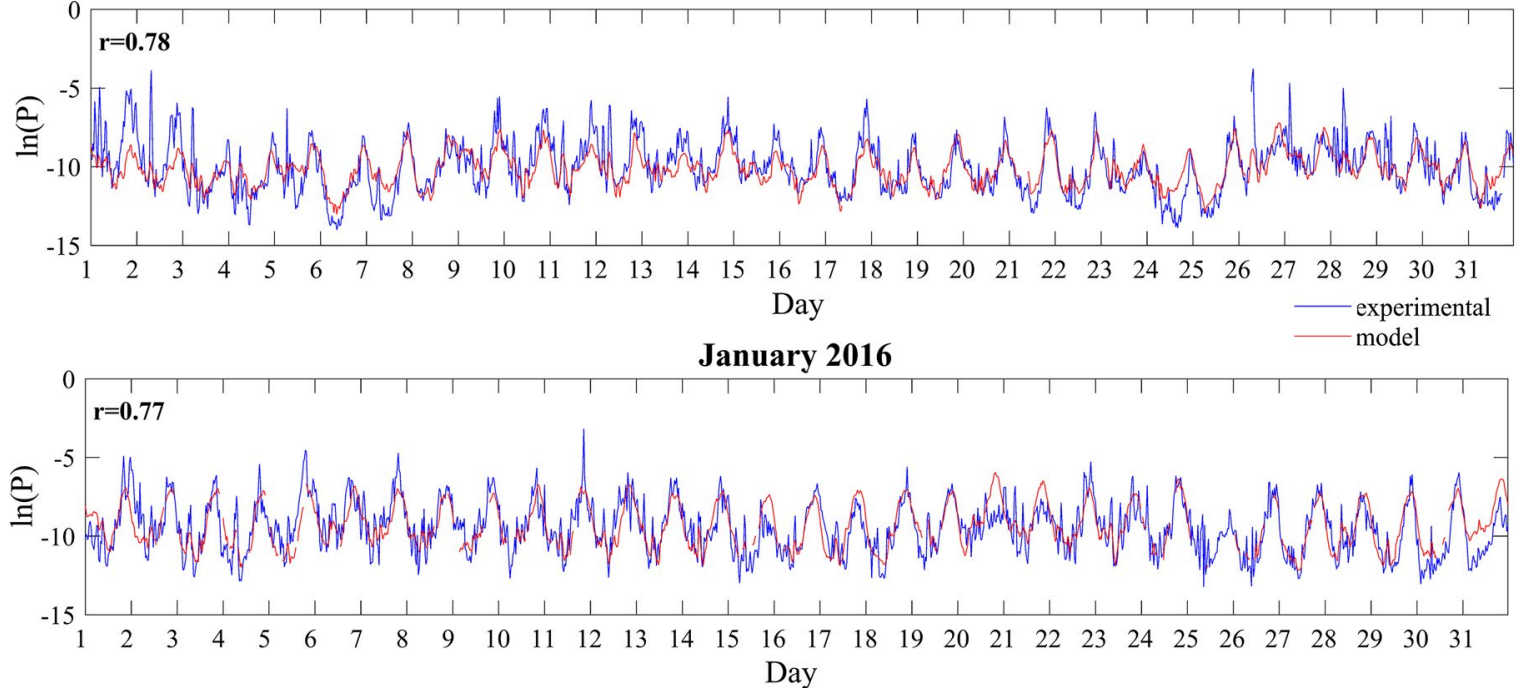

Fig. 11 Pc1-2 power model. Top panels: the UT dependence on model coefficients. Middle and bottom panels: a comparison between experimental and model $P$ values for March 2008 and January 2016 


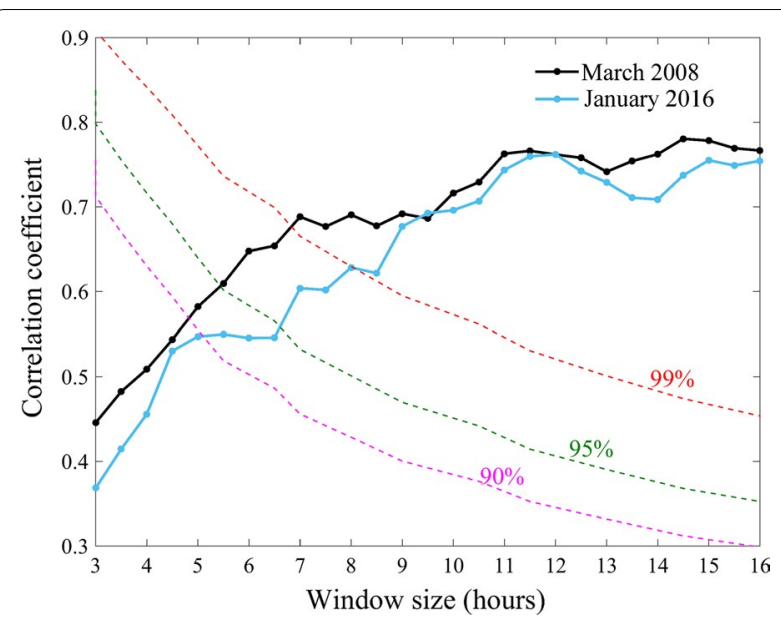

Fig. 12 Correspondence time scales. The correlation coefficients between model and experimental data computed in different time windows. The black and blue lines refer to March 2008 and January 2016, respectively

contrast, examining the MLT dependence, in addition to a main peak of occurrence around noon, also observed in the power analysis, there is a minor peak near midnight. While polarized waves represent only a small fraction of the events observed around noon, midnight events are generally polarized waves. Both noon and midnight polarized waves exhibit a similar frequency distribution. The ellipticity values indicate primarily linearly polarized waves, with the major axis directed at $\sim 50^{\circ}$ with respect to the $H$ component. Our results suggest that the power peak at noon is due primarily to unpolarized waves, with a minor contribution represented by linearly polarized waves. This observation is interpreted as waves propagated far from the injection region up to the TNB latitude, in the high-latitude ionospheric waveguide along the meridional direction (Kim et al. 2011). The midnight events are very few with respect to the noon events, but are generally consistent with linearly polarized waves.

Considering geomagnetic and SW conditions, we found that the noon peak is associated with time intervals characterized by very high SW densities and associated high AE values (Usanova et al. 2012), while the midnight peak is entirely associated with high AE values. In addition, the Pc1-2 power appears significantly related to $\mathrm{AE}$ through the day, particularly at midnight, and to $n_{\mathrm{SW}}$ only around noon. Based on these results, we hypothesize that this observation indicates different sources for Pc1-2 waves observed at TNB. In the noon sector, compressions of the outermost closed magnetospheric field lines by the SW are important; in the declining phase of the solar cycle SW pressure variations are generally associated with the fast stream occurrence, which also produces high magnetospheric activity (high $\mathrm{AE}$ ). We note that the noon maximum of both power and event occurrence is slightly asymmetric, shifted to the post-noon sector, in agreement with the results of previous studies. At geosynchronous orbit, a similar MLT occurrence of EMIC waves associated with SW pressure peaks was documented in Clausen et al. (2011) and Park et al. (2016); on the ground, a post-noon occurrence maximum (12-13 MLT) was observed by Kurazhkovskaya et al. (2007) at the Mirny Observatory $\left(77^{\circ} \mathrm{S}\right.$ invariant latitude, Antarctica) for magnetic impulses accompanied by Pc1 pulsations. This feature could be due to the impact of SW high density regions leading fast streams (Corotating Interaction Regions), mostly on the post-noon magnetopause, due to the IMF average orientation at the Earth's orbit at $\sim 45^{\circ}$ with respect to the Sun-Earth direction (Rostoker and Sullivan 1987; Villante et al. 2001). In the midnight sector, Pc1-2 waves are likely caused by substorm/stormrelated ion instability occurring in the plasma sheet. The significant correlation observed between Pc1-2 power and both $\mathrm{AE}$ index and $\mathrm{SW}$ density allows us to develop a simple model to estimate Pc1-2 power from the two parameters. The model fits the experimental data well, and for time intervals outside the dataset used for the model, up to time scales as short as 6-7 h. Taking into account that the wave power attenuation along the ionospheric waveguide is $\sim 10 \mathrm{~dB} / 1000 \mathrm{~km}$ (Kim et al. 2011), we believe that the applicability of the model can be extended from auroral latitudes up to latitudes near the geomagnetic pole.

The occurrence of events shows a dependence on the solar cycle, opposite with respect to the power dependence, with an increasing number of events through the years. This feature is consistent with previous results, which showed a strong negative correlation between high-latitude Pc1 events and solar activity, and agrees with the negative correlation between SW density and solar activity (Mursula et al. 1994; Kangas et al. 1998).

We suggest that Pc1-2 events observed around noon at TNB could be due to waves generated just inside the magnetopause, near the equatorial plane, by SW compressions, which was observed in the dayside outer magnetosphere by Engebretson et al. (2002) and Usanova et al. (2012). These waves propagate along the outermost closed field lines into the ionosphere; then, they can propagate along the ionospheric waveguide far from the injection region up to the TNB latitude. For example, at noon, this is over $\sim 500-600 \mathrm{~km}$, the average distance of the station from the closed field lines. We hypothesize that due to the closeness of the station to the cusp around noon, TNB is subject to a mixture of different waves and only very strong signals can maintain their properties, such as the polarization degree. For example, 


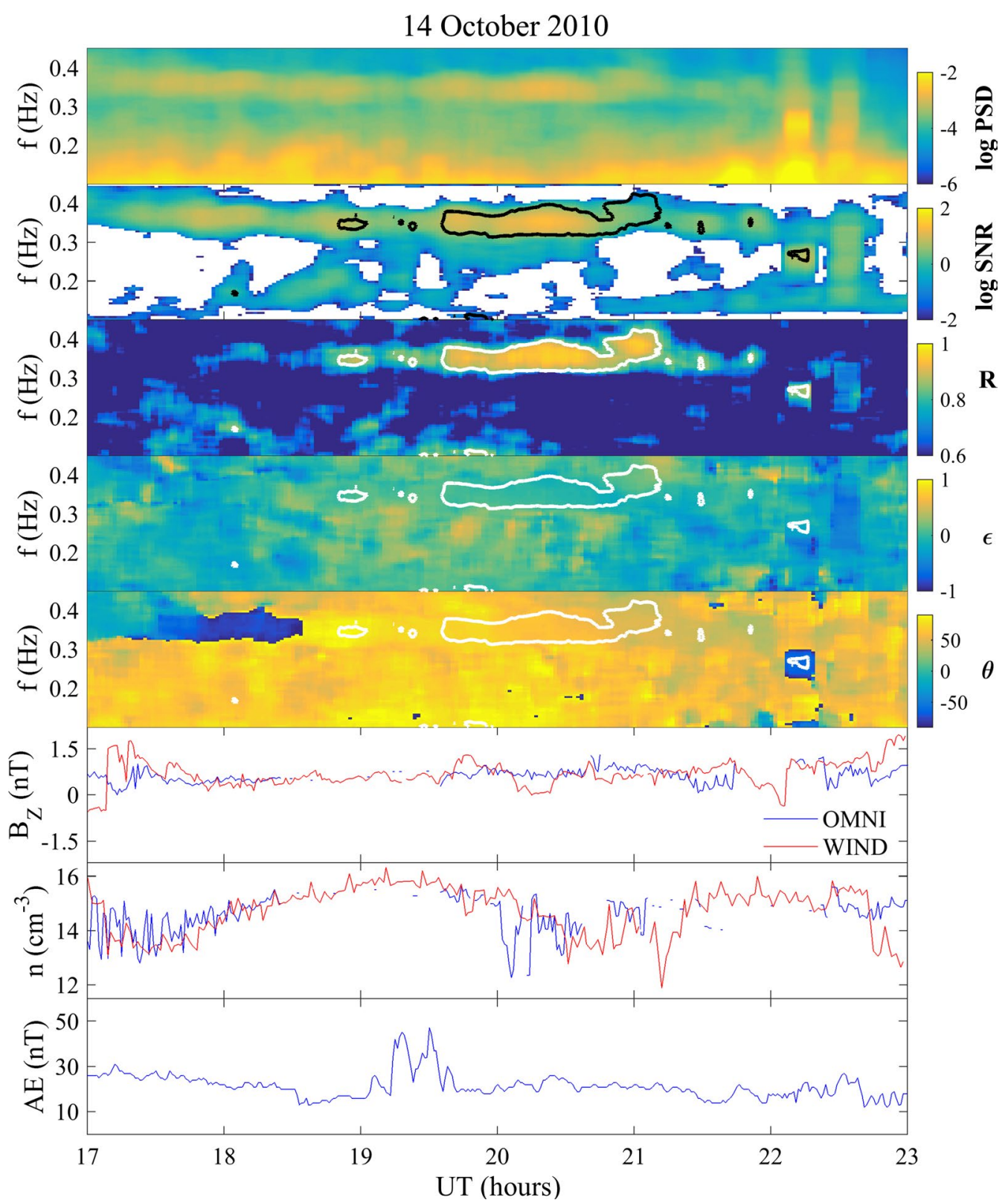

Fig. 13 Noon case study. The dynamical power spectrum, signal-to-noise ratio (white areas correspond to SNR < 0), polarization ratio, ellipticity, azimuthal angle, IMF $B_{z}$ component, SW density, and AE index during the October 14, 2010, event. In addition to the OMNI data (blue line), which show large gaps, the WIND data are also plotted (red line). Black and white contours encircle values corresponding to a polarization ratio $R>0.85$

the polarized waves of the selected noon event are associated with a long duration magnetospheric compression due to very high SW density and show an ellipticity close to zero, which indicates a linear polarization, as expected for waves propagating far in the waveguide (Greifinger and Greifinger 1968; Greifinger 1972a, b).

Nighttime events are less common, probably because in the dark sector, TNB is embedded in the polar cap, with local field lines far from the magnetospheric regions from which waves originate (as the plasma sheet). The observed waves are generally polarized, likely because additional superimposed signals are absent, as suggested by the lower power content in the nighttime spectra (Fig. 4). Pc1-2 waves are observed at TNB during perturbed geomagnetic conditions, when ion instability increases in the plasma sheet. This result is in agreement with the magnetospheric observations by Usanova et al. 2012, who also detected EMIC waves just before 


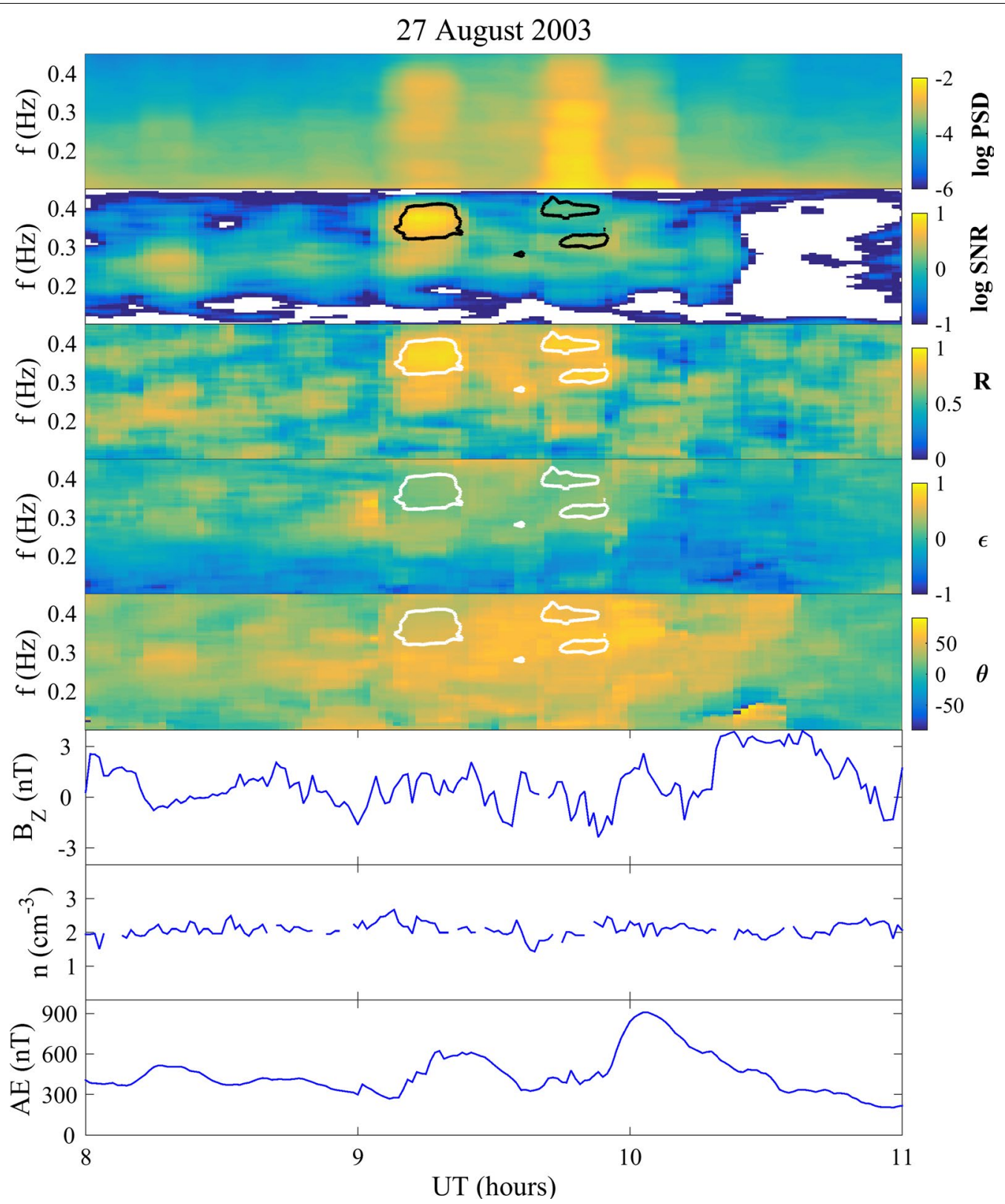

Fig. 14 Midnight case study. The dynamical power spectrum, signal-to-noise ratio, polarization ratio, ellipticity, azimuthal angle, IMF $B_{z}$ component, SW density, and $A E$ index during the August 27, 2003, event. Black and white contours encircle values corresponding to a polarization ratio $R>0.85$

midnight at $L=9-10$ during moderate and enhanced substorm activity. The selected nighttime event has a short duration, occurred in correspondence with a geomagnetic substorm, and shows a linear ellipticity. These features are consistent with a wave packet propagated toward the high-latitude ionosphere along magnetotail field lines, from the plasma sheet, and then along the ionospheric waveguide up to TNB.

In conclusion, the main results of our statistical study of Pc1-2 waves at southern polar latitudes are as follows:
1. Pc1-2 waves are observed around local magnetic noon and midnight, and are, respectively, associated with SW compressions of the magnetopause and substorm/stormrelated instabilities.

2. Polarized waves, primarily observed around midnight, show an almost linear polarization, suggesting wave propagation along a meridional ionospheric waveguide, from the injection region up to the latitude of Terra Nova Bay. 
3. Based on these results, we propose a simple model to estimate Pc1-2 power variations at auroral and polar latitudes that depend on the geomagnetic activity and SW density.

\section{Authors' contributions}

MR and MM performed the data analysis. MR and PF drafted the manuscript. PF and MDL participated in the study design and interpretation of results. All authors read and approved the final manuscript.

\section{Acknowledgements}

This research activity was supported by the Italian PNRA (Programma Nazionale di Ricerche in Antartide, PdR2013/B2.09). The authors acknowledge J.H. King and N. Papatashvilli at NASA and CDAWeb for solar wind data (http:// cdaweb.gsfc.nasa.gov). Measurements of the magnetic field fluctuations at Terra Nova Bay can be requested from Marcello De Lauretis at the following e-mail address: marcello.delauretis@aquila.infn.it. The authors thank both reviewers for their helpful comments and suggestions.

\section{Competing interests}

The authors declare that they have no competing interests.

\section{Consent to participate}

Not applicable.

\section{Consent to publish}

Not applicable.

\section{Ethics approval}

Not applicable.

\section{Publisher's Note}

Springer Nature remains neutral with regard to jurisdictional claims in published maps and institutional affiliations.

Received: 7 June 2017 Accepted: 25 October 2017

Published online: 03 November 2017

\section{References}

Anderson BJ, Erlandson RE, Zanetti LJ (1992a) A statistical study of Pc 1-2 magnetic pulsations in the equatorial magnetosphere: 1. Equatorial occurrence distributions. J Geophys Res 97(A3):3075-3088. https://doi. org/10.1029/91JA02706

Anderson BJ, Erlandson RE, Zanetti LJ (1992b) A statistical study of PC 1-2 magnetic pulsations in the equatorial magnetosphere: 2. Wave properties. J Geophys Res 97(A3):3089-3101. https://doi.org/10.1029/91JA02697

Anderson BJ, Denton RE, Ho G, Hamilton DC, Fuselier SA, Strangeway RJ (1996) Observational test of local proton cyclotron instability in the Earth's magnetosphere. J. Geophys. Res. 101:21527-21544. https://doi. org/10.1029/96JA01251

Anqin C, Jiawei L, Guanglin Y, Jingsong W (2008) Calculating auroral oval pattern by AE Index. Acta Meteorol Sin 22(1):91-96

Blum LW, Halford A, Millan R, Bonnell JW, Goldstein J, Usanova M, Engebretson M, Ohnsted M, Reeves G, Singer H et al (2015) Observations of coincident EMIC wave activity and duskside energetic electron precipitation on 18-19 January 2013. Geophys Res Lett 42:5727-5735. https://doi. org/10.1002/2015GL065245

Bolshakova O, Troitskaya V, Ivanov K (1980) High-latitude Pc1-2 geomagnetic pulsations and their connection with location of the dayside polar cusp. Planet Space Sci 28:1-7. https://doi.org/10.1016/0032-0633(80)90098-7

Clausen LBN, Baker JBH, Ruohoniemi JM, Singer HJ (2011) ULF wave characteristics at geosynchronous orbit during the recovery phase of geomagnetic storms associated with strong electron acceleration. J Geophys Res 116:A09203. https://doi.org/10.1029/2011JA016666

Clilverd MA, Rodger CJ, Moffat-Griffin T, Spanswick E, Breen P, Menk FW, Grew RS, Hayashi K, Mann IR (2010) Energetic outer radiation belt electron precipitation during recurrent solar activity. J Geophys Res 115:A08323. https://doi.org/10.1029/2009JA015204

Clopper CJ, Pearson ES (1934) The use of confidence or fiducial limits illustrated in the case of the binomial. Biometrika 26:404-413

De Lauretis M, Francia P, Vellante M, Piancatelli A, Villante U, Di Memmo D (2005) ULF geomagnetic pulsations in the southern polar cap: Simultaneous measurements near the cusp and the geomagnetic pole. J Geophys Res 110:A11204. https://doi. org/10.1029/2005JA011058

De Lauretis M, Francia P, Regi M, Villante U, Piancatelli A (2010) Pc3 pulsations in the polar cap and at low latitude. J Geophys Res 115:A11223. https:// doi.org/10.1029/2010JA015967

Dyrud L, Engebretson M, Posch J, Hughes W, Fukunishi H, Arnoldy R, Newell P, Horne R (1997) Ground observations and possible source regions of two types of Pc 1-2 micropulsations at very high latitudes. J Geophys Res 102:27011-27027. https://doi.org/10.1029/97ja02191

Engebretson M, Peterson W, Posch J, Klatt M, Anderson B, Russell C, Singer H, Arnoldy R, Fukunishi H (2002) Observations of two types of Pc 1-2 pulsations in the outer dayside magnetosphere. J Geophys Res. https://doi. org/10.1029/2001ja000198

Engebretson MJ, Lessard MR, Bortnik J, Green JC, Horne RB, Detrick DL, Weatherwax AT et al (2008) Pc1-Pc2 waves and energetic particle precipitation during and after magnetic storms: superposed epoch analysis and case studies. J Geophys Res. https://doi. org/10.1029/2007ja012362

Fowler RA, Kotick BJ, Elliott RD (1967) Polarization analysis of natural and artificially induced geomagnetic micropulsations. J Geophys Res 72(11):28712883. https://doi.org/10.1029/JZ072i011p02871

Francia P, Regi M, De Lauretis M (2015) Signatures of the ULF geomagnetic activity in the surface air temperature in Antarctica. J Geophys Res 120(4):2452-2459. https://doi.org/10.1002/2015JA021011

Fujita S, Tamao T (1988) Duct propagation of hydromagnetic waves in the upper ionosphere,1, Electromagnetic field disturbances in high latitudes associated with localized incidence of a shear Alfvénwave. J Geophys Res 93(A12): 14665-14673. doi:10.1029/JA093iA12p14665

Greifinger P (1972a) lonospheric propagation of oblique hydromagnetic plane waves at micropulsation frequencies. J Geophys Res 77(13):2377-2391. https://doi.org/10.1029/JA077i013p02377

Greifinger P (1972b) micropulsations from a finite source. J Geophys Res 77(13):2392-2396. https://doi.org/10.1029/JA077i013p02392

Greifinger C, Greifinger PS (1968) Theory of hydromagnetic propagation in the ionospheric waveguide. J Geophys Res 73(23):7473-7490. https://doi. org/10.1029/JA073i023p07473

Guglielmi AV, Potapov AS, Russel CT (2000) The ion-cyclotron resonator in the magnetosphere. J Exp Theor Phys Lett 72(6):432-435

Jacobs J, Watanabe T (1964) Micropulsation whistlers. J Atmos Terr Phys 26(8):825-826

Kangas J, Guglielmi A, Pokhotelov O (1998) Morphology and physics of shortperiod magnetic pulsations. Space Sci Rev 83:435-512

Kim H, Lessard M, Engebretson M, Young M (2011) Statistical study of PC1-2 wave propagation characteristics in the high-latitude ionospheric waveguide. J Geophys Res. https://doi.org/10.1029/2010ja016355

Kurazhkovskaya NA, Klain Bl, Dovbnya BV (2007) Patterns of simultaneous observations of high-latitude magnetic impulses (MIEs) and impulsive bursts in the Pc1-2 band. J Atmos Solar Terr Phys 69:1680-1689

Manchester RN (1966) Propagation of Pc 1 micropulsations from high to low latitudes. J Geophys Res 71(15):3749-3754. https://doi.org/10.1029/ JZ0711015p03749

Menk FW (2011) Magnetospheric ULF waves: a review. In: The dynamic magnetosphere, pp 223-256. Springer. https://doi. org/10.1007/978-94-007-0501-2_13

Menk FW, Fraser BJ, Hansen HJ, Newell PT, Meng C-I, Morris RJ (1993) Multistation observations of PC 1-2 ULF pulsations in the vicinity of the polar cusp. J Geomagn Geoelectr 45:1159-1173. https://doi.org/10.1029/95ja00768

Mironova I, Aplin K, Arnold F, Bazilevskaya G, Harrison R, Krivolutsky A, Nicoll K, Rozanov E, Turunen E, Usoskin I (2015) Energetic particle influence on the Earth's atmosphere. Space Sci Rev 194(1-4):1-96. https://doi.org/10.1007/ s11214-015-0185-4

Mursula K, Blomberg L, Lindqvist P, Marklund G, Bräysy T, Rasinkangas R, Tanskanen P (1994) Dispersive Pc1 bursts observed by Freja. Geophys Res Lett 21(17):1851-1854. https://doi.org/10.1029/94gl01584 
Mursula K, Bräysy T, Niskala K, Russell CT (2001) PC1 pearls revisited: structured electromagnetic ion cyclotron waves on polar satellite and on ground. J Geophys Res Space Phys 106(A12):29543-29553

Park J-S, Kim K-H, Shiokawa K, Lee D-H, Lee E, Kwon H-J, Jin H, Jee G (2016) EMIC waves observed at geosynchronous orbit under quiet geomagnetic conditions $(K p \leq 1)$. J Geophys Res Space Phys 121:1377-1390. https:// doi.org/10.1002/2015JA021968

Paulson KW, Smith CW, Lessard MR, Engebretson MJ, Torbert RB, Kletzing CA (2014) In situ observations of PC1 pearl pulsations by the Van Allen Probes. Geophys Res Lett 41:1823-1829. https://doi. org/10.1002/2013GL059187

Paulson KW, Smith CW, Lessard MR, Torbert RB, Kletzing CA, Wygant JR (2017) In situ statistical observations of Pc1 pearl pulsations and unstructured EMIC waves by the Van Allen Probes. J Geophys Res Space Phys 122:105-119. https://doi.org/10.1002/2016JA023160

Ponomarenko PV, Fraser BJ, Menk FW, Ables ST, Morris RJ (2002) Cusp-latitude Pc3 spectra: band-limited and power-law components. Ann Geophys 20:1539-1551. https://doi.org/10.5194/angeo-20-1539-2002

Popecki M, Arnoldy R, Engebretson MJ, Cahill LJ Jr. (1993) High-latitude ground observations of Pc 1/2 micropulsations. J Geophys Res 98(A12):2148121491. https://doi.org/10.1029/93JA02539

Rasinkangas R, Mursula K (1998) Modulation of magnetospheric emic waves by Pc 3 pulsations of upstream origin. Geophys Res Lett 25(6):869-872

Regi M, De Lauretis M, Francia P (2014) The occurrence of upstream waves in relation with the solar wind parameters: a statistical approach to estimate the size of the foreshock region. Planet Space Sci 90:100-105. https://doi. org/10.1016/j.pss.2013.10.012

Regi M, De Lauretis M, Francia P (2015) Pc5 geomagnetic fluctuations in response to solar wind excitation and their relationship with relativistic electron fluxes in the outer radiation belt. Earth Planets Space. https:// doi.org/10.1186/s40623-015-0180-8

Regi M, De Lauretis M, Redaelli G, Francia P (2016) ULF geomagnetic and polar cap potential signatures in the temperature and zonal wind reanalysis data in Antarctica. J Geophys Res 121(1):286-295. https://doi. org/10.1002/2015JA022104

Regi M, Redaelli G, Francia P, De Lauretis M (2017) ULF geomagnetic activity effects on tropospheric temperature, specifichumidity, and cloud cover in Antarctica, during 2003-2010. J Geophys Res Atmos 122:6488-6501. doi:10.1002/2017JD027107
Rodger CJ, Raita T, Clilverd MA, Seppala A, Dietrich S, Thomson NR, Ulich T (2008) Observations of relativistic electron precipitation from the radiation belts driven by EMIC waves. Geophys Res Lett 35:L16106. https://doi. org/10.1029/2008GL034804

Rostoker G, Sullivan BT (1987) Polarization characteristics of Pc5 magnetic pulsations in the dusk hemisphere. Planet Space Sci 35:429

Schmitter ED (2010) Remote auroral activity detection and modeling using low frequency transmitter signal reception at a midlatitude site. Ann Geophys 28(9):1807-1811. https://doi.org/10.5194/angeo-28-1807-2010

Summers WR, Fraser BJ (1972) Polarization properties of PC 1 micropulsations at low latitudes. Planet Space Sci 20(8):1323-1335. https://doi. org/10.1016/0032-0633(72)90019-0

Tepley L, Landshoff RK (1966) Waveguide theory for ionospheric propagation of hydromagnetic emissions. J Geophys Res 71(5):1499-1504. https://doi. org/10.1029/JZ071i005p01499

Tetrick SS, Engebretson MJ, Posch JL, Olson CN, Kletzing CA, Smith CW, Thaller SA, Wygant JR, Reeves GD, MacDonald EA, Fennell JF (2017) Location of intense electromagnetic ion cyclotron (EMIC) wave events relative to the plasmapause: Van Allen Probes observations. J Geophys Res Space Phys. https://doi.org/10.1002/2016JA023392

Usanova ME, Mann IR, Rae IJ, Kale ZC, Angelopoulos V, Angelopoulos JW, Glassmeier K-H, Auster HU, Singer HJ (2008) Multipoint observations of magnetospheric compression-related EMIC PC1 waves by THEMIS and CARISMA. Geophys Res Lett 35:L17S25. https://doi. org/10.1029/2008GL034458

Usanova ME, Mann IR, Bortnik J, Shao L, Angelopoulos V (2012) THEMIS observations of electromagnetic ion cyclotron wave occurrence: dependence on AE, SYMH, and solar wind dynamic pressure. J Geophys Res 117:A10218. https://doi.org/10.1029/2012JA018049

Villante U, Francia P, Lepidi S (2001) Pc5 geomagnetic field fluctuations at discrete frequencies at a low latitude station. Ann Geophys 19:321-325

Zhou X-W, Russell C, Le G, Fuselier S, Scudder J (1999) The polar cusp location and its dependence on dipole tilt. Geophys Res Lett 26:429-432. https:// doi.org/10.1029/1998gl900312

Zhou X-W, Russell C, Le G, Fuselier S, Scudder J (2000) Solar wind control of the polar cusp at high altitude. J Geophys Res 105:245-251

\section{Submit your manuscript to a SpringerOpen ${ }^{\circ}$ journal and benefit from:}

- Convenient online submission

- Rigorous peer review

- Open access: articles freely available online

- High visibility within the field

- Retaining the copyright to your article

Submit your next manuscript at $\boldsymbol{\nabla}$ springeropen.com 